\title{
ISPS 2008 editorial: the 18th ASME annual conference on information storage and processing systems, Santa Clara, CA, USA
}

\author{
Jen-Yuan (James) Chang
}

Published online: 18 September 2009

(C) Springer-Verlag 2009

I am pleased to be invited to act as a guest editor for this special issue of Information Storage Processing Systems 2008 (aka ISPS 2008) which features outstanding papers from the 18th American Society of Mechanical Engineers (ASME) Annual Conference on Information Storage and Processing Systems, which was held on June 16-17, 2008 in Santa Clara University, Santa Clara, CA, USA and organized and sponsored by ASME ISPS Division.

ISPS 2008 is a unique conference brought together both American and International researchers in data storage, mechatronics, and intelligent systems. The conference featured 2 days of multiple-track oral presentations in 24 technical sessions addressing latest researches, developments, and applications that include:

- Actuators and suspensions

- Biomedical and smart machines

- Image processing and consumer electronics

- Micro/nano technologies

- Optical storage and technologies

- Servo control technologies

- Shock and flow induced vibrations

- Spindle motor and acoustics

- Tape storage and flexible media mechanics

- Tribology and head-disk interface

ISPS 2008 provides an idea forum for experts and researchers from industry and academia to foster synergies in multi-disciplinary areas of magnetic and optical storage systems such as rigid disk, flexible disk, tape media, and optical storage systems, information processing systems

J.-Y. (James) Chang ( $\square)$

School of Engineering and Advanced Technology, Massey

University, North Shore City, Auckland 0745, New Zealand

e-mail: J.Y.Chang@massey.ac.nz such as copiers, printers, digital cameras, scanners, data servers, automated teller machines, and intelligent systems including biomedical equipment, nano/micro systems, and mechatronics systems.

ISPS 2008 is also an international conference having high quality contributions from countries including USA, Korea, Japan, Singapore, Taiwan, Canada, Thailand, China, New Zealand, and Iran. Significant percentages of papers presented in the conference are results of industryuniversity research collaborations and multi-national collaborative researches. To signify this increasing trend of global multi-disciplinary research collaboration, ISPS 2008 offers two invited talks addressing cutting edge research topics on "Nanoparticles Secreted from Ivy Rootlets for Surface Climbing" presented by Dr. Maozi Liu of Agilent Technology Inc., USA, and "Flexible Display Technology for the Soldier" presented by Dr. Eric Forsythe of Army Research Laboratory, USA. For his significant contributions to commercialization of MEMS technologies, Dr. Kurt Peterson was invited as the conference keynote speaker who gave an exciting and interesting speech on "The Rise of MEME" in the ISPS 2008 conference dinner.

ISPS 2008 as well recognizes technical contributions from researchers and students. In addition to a Best Conference Paper Award, starting from 2008 and sponsored by ASME ISPS Division, ISPS 2008 offers Best Track Paper Awards for outstanding papers in each technical track. To encourage student participation in the conference as well as to promote student research in information storage and processing systems, ISPS 2008 provides two ISPS Division Graduate Student Fellowships each consists of a monetary award of fifteen hundred US dollars and a free conference registration, and six Conference Scholarships to waive graduate student's conference registration fees. Both American and International researchers and students were 
recognized through the ISPS Awards and student program in ISPS 2008.

To archive the papers presented in ISPS 2008, authors of all papers submitted to ISPS 2008 were encouraged to submit a full paper to this special issue. All submitted papers went through a rigorous peer-review process. Many reviewers are in fact world leading experts in relevant fields. Many papers have been substantially revised more than twice before they are published. Out of the 88 papers presented in ASME ISPS 2008, there were 51 papers submitted to this special issue for review, 40 papers were accepted, 10 papers were rejected, and 1 paper was withdrawn.

The publication of the Special Issue signifies the closure of ISPS 2008 activities. I would like to express my sincere appreciation to many people who make ISPS 2008 and this Special Issue possible. Among the long list, I thank Professor Bharat Bhushan of Ohio State University for his coordination with the publisher to publish the Special Issue in a timely manner. I thank Professor I. Y. (Steve) Shen of
University of Washington and Professor Frank Talke of University of California, San Diego for sharing their insight on the conference technical programs and preparation. Special thank is given to Santa Clara University for use of its facilities for the ISPS 2008 conference. I thank Dr. Neal Schirle of Hitachi GST for his efforts as the conference treasurer to make all necessary arrangements with the university. I would like to thank all session organizers, session chairs, presenters, and the ASME ISPS Executive Committee Members for their efforts and assistance in making ISPS 2008 possible. I sincerely thank reviewers who review the manuscripts in a thorough and constructive manner. Without the fast responses from all reviewers, this Special Issue will not appear so quickly. Lastly but not the least, I thank the authors for contributing their time in writing, preparing, and submitting papers to this Special Issue. I wish you a successful year, and I look forward to seeing you and working with you all in the next ASME ISPS conference. 